\title{
THE INVESTIGATION OF SEPARABILITY OF PARTICLES SMALLER THAN 5 mm BY EDDY CURRENT SEPARATION TECHNOLOGY. PART I: ROTATING TYPE EDDY CURRENT SEPARATORS
}

\author{
SHUNLI ZHANG ${ }^{\mathrm{a}}$, PETER C. REM ${ }^{\mathrm{b}, *}$ and \\ ERIC FORSSBERG ${ }^{\mathrm{a}}$ \\ ${ }^{a}$ Division of Mineral Processing, Lulea University of Technology, S-97187 \\ Luleå, Sweden; ' Department of Raw Materials Technology, \\ Delft University of Technology, $2628 R X$ Delft, The Netherlands
}

(Received 3 November 1998; Accepted 17 December 1998)

\begin{abstract}
Owing to the growing emergence of the end-of-life electrical and electronic products with complex material structures and an ever-diminishing particle size of the valuable metals involved, development of eddy current separators (ECS) has been targeting selective separation of small non-ferrous metal particles smaller than $5 \mathrm{~mm}$. Separability of various materials smaller than $5 \mathrm{~mm}$, including fine copper wires, has been investigated using ECS with various design concepts. The present research work is divided into two parts, with Part I focusing on the rotating type ECS which are today common in practice, and with Part II dedicated to the ECS with novel concepts such as wet ECS technology. In Part I, three rotating belted-drum ECS were employed, which are manufactured by Bakker Magnetics, the Netherlands, Huron Valley Steel Co., US, and Eriez Magnetics, UK respectively. It is found that the belted-drum ECS are effective for separating materials below $5 \mathrm{~mm}$ if the magnetic drum rotates in opposite direction to the conveyor belt. The separation principle, particularly the "backward phenomenon" of the rotating type ECS for small particles has been unravelled in the present study. Moreover, separation of $\mathrm{Al}$ from the $0-10 \mathrm{~mm}$ fraction of electronic scrap has been conducted. The results obtained demonstrate that the belted-drum ECS with appropriate design may be applicable for separation of small aluminum particles from electronic scrap.
\end{abstract}

Keywords: Rotating eddy current separator; Separability; Eddy current force; Backward phenomenon; Electronic scrap

\footnotetext{
* Corresponding author. E-mail: P.C.Rem@,ta.tudelft.nl.
} 


\section{INTRODUCTION}

The design and performance of the rotating belted-drum type eddy current separators have been improved substantially in the last ten years, due primarily to the advance of the magnet materials and magnet configurations, and to a better understanding of the separation mechanisms [1-3]. Yet, problems associated with separation of small particles, remain in particular, those smaller than $5 \mathrm{~mm}$. Therefore, the current development of eddy current separators (ECS) has been directed to selective separation of small non-ferrous metal particles.

In the present study, separability of various materials of $3 \mathrm{~mm}$ size, including fine copper wires, has been investigated using different ECS with various design concepts. On the basis of the present investigation and of the critical comparison of different ECS, each with a unique design, it can be anticipated that a novel ECS capable of separating metal particles smaller than $5 \mathrm{~mm}$ with both a high selectivity and a large capacity will be developed.

This research work is divided into two parts, with Part I focusing on the rotating type ECS which are presently common in practice and with Part II dedicated to ECS with novel concepts such as wet eddy current separation technology. In Part I, three rotating belted-drum ECS were employed, which are manufactured by Bakker Magnetics, the Netherlands, Huron Valley Steel Co., US, and Eriez Magnetics, UK respectively. The separation results obtained from those three devices are analyzed, in terms of various separation forces and the separation mechanisms for small particles are discussed in the present study. Further, the aluminum recovery from the $0-10 \mathrm{~mm}$ fraction of electronic scrap has been conducted using two of the three devices. Additionally, the present results are evaluated to demonstrate that modern ECS may well be progressed to separate fine metal particles like copper wires effectively and efficiently.

\section{EXPERIMENTAL}

\subsection{Materials}

Aluminum ( $\mathrm{Al})$, copper $(\mathrm{Cu})$ and polyvinyl chloride (PVC) particles of $3 \mathrm{~mm}$ size were obtained by cutting pure materials with a 


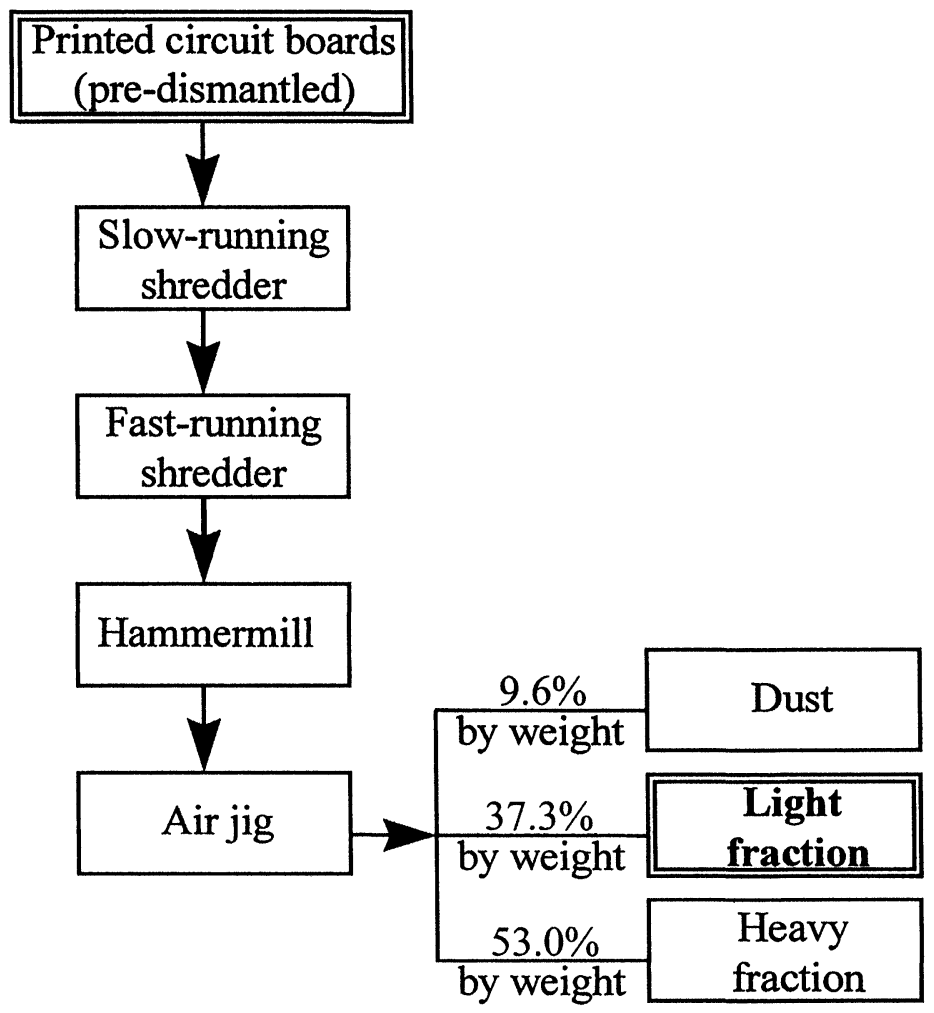

FIGURE 1 The process producing the light fraction which is used in the present study.

semi-automatic cutting machine. A $3 \mathrm{~kg}$ electronic scrap sample was obtained in the way shown in Fig. 1. The light fraction of the air jig separation, consisting essentially of aluminum and various plastics, was used in the present study. Its particle size distribution is presented in Fig. 2.

\subsection{Equipment to be Used}

The rotating belted-drum eddy current separators (RBECS) used are illustrated in Fig. 3. In this study, three types of RBECS, manufactured by Bakker Magnetics, the Netherlands (Bakker ECS, Model BM 29.701/18), Huron Valley Steel Co., US (Huron ECS, Model MK.IV-36/24), and Eriez Magnetics, UK (Eriez ECS, Model 1222) 


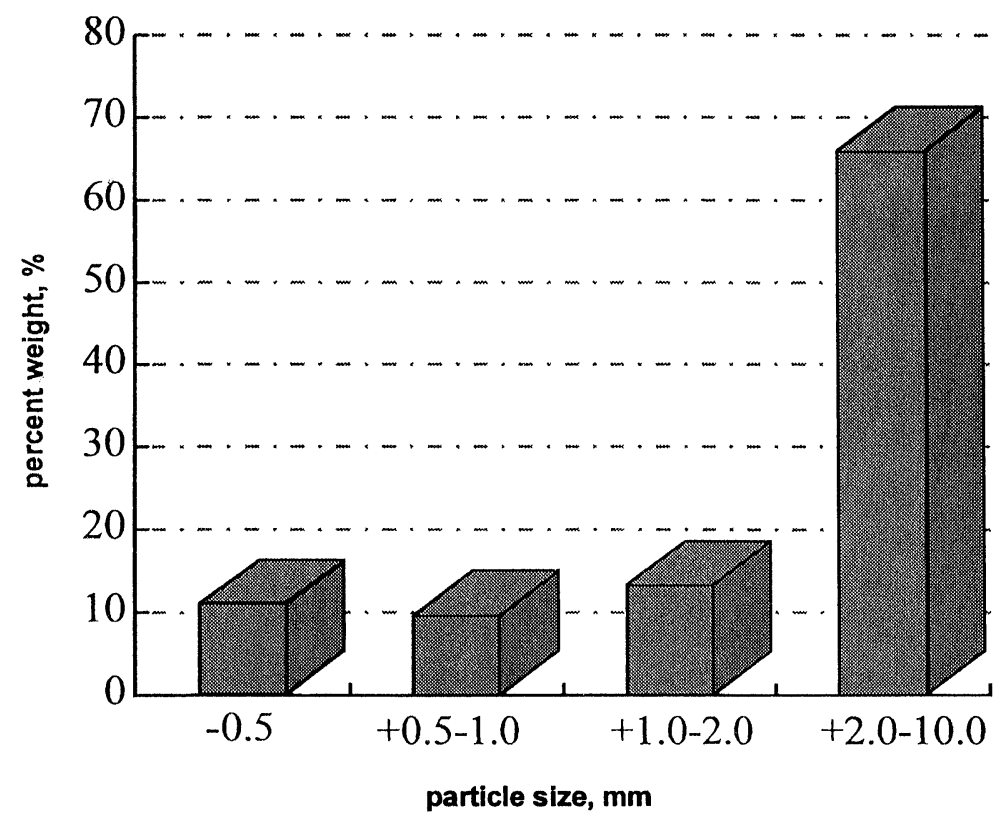

FIGURE 2 The particle size distribution of the light fraction from the air jig separation of shredded printed circuit boards.

respectively, were employed. Several major characteristics of the equipment, that are relevant to their performance, are compared in Table I.

\subsection{The Separability Investigation}

The separability of the materials was characterized by their distribution in an array of the collection bins which were placed in front of the conveyor belt pulley, as shown in Fig. 3. Twelve collection bins, each with dimensions of $400 \times 40 \times 90$ (length $\times$ width $\times$ height) $\mathrm{mm}$, were used. The material distribution was analyzed by its percent weight in each collection bin such that:

$$
(P W)_{i j}=\frac{W_{i j}}{\sum_{j=1}^{12} W_{i j}} \times 100 \%,
$$

where $(P W)_{\mathrm{ij}}$ is the percent weight of the $i$ th material in the $j$ th collection bin, and $W_{i j}$ the weight of the $i$ th material in the $j$ th collection bin. 


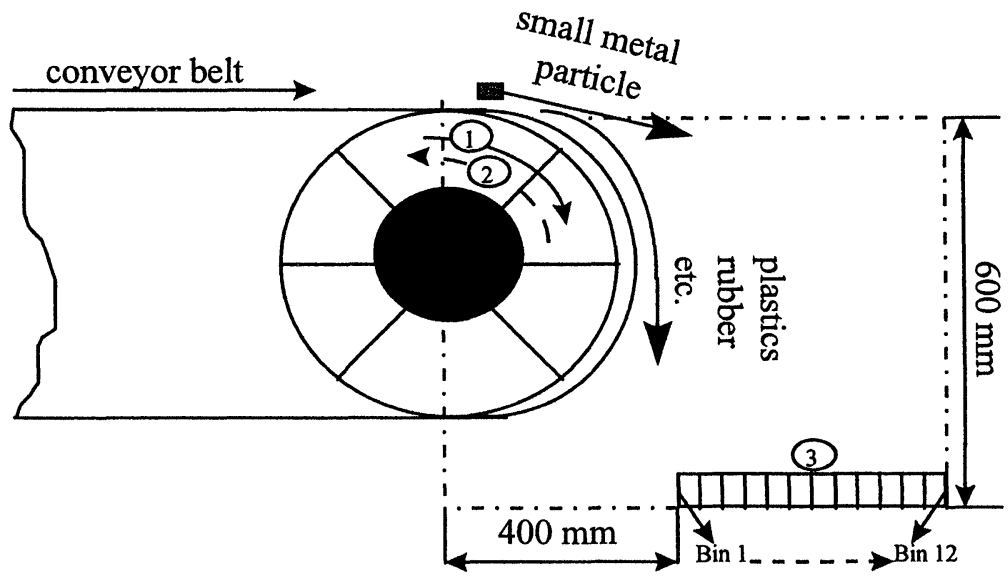

(1) Magnetic drum rotates in a Forward mode

(2) Magnetic drum rotates in a Backward mode

(3) 12 collection bins

FIGURE 3 Schematic presentation of belted-drum eddy current separators illustrating the separation principle.

TABLE I Major characteristics of ECS used in the study

\begin{tabular}{lcclc}
\hline Name & $\begin{array}{c}\text { Magnetic strength } \\
\text { on the surface of } \\
\text { the shell (Tesla) }\end{array}$ & $\begin{array}{c}\text { Number of } \\
\text { pairs of } \\
\text { magnets }\end{array}$ & $\begin{array}{c}\text { Rotational } \\
\text { directions of the } \\
\text { magnetic drum }\end{array}$ & $\begin{array}{c}\text { Maximum speed } \\
\text { of the magnetic } \\
\text { drum (rpm/rps) }\end{array}$ \\
\hline Bakker ECS & 0.38 & 9 & Forward and Backward & $3000 / 50$ \\
Huron ECS & 0.26 & 12 & Forward & $3000 / 50$ \\
Eriez ECS & 0.35 & 11 & Forward and Backward & $6500 / 108$ \\
\hline
\end{tabular}

The separability of small particles with Eriez ECS was carried out by adjusting its splitters, instead of using the collection bins.

\section{EXPERIMENTAL RESULTS}

\subsection{Separability of $3 \mathrm{~mm}$ Particles}

Binary mixtures of $\mathrm{Al} / \mathrm{Cu}$ and $\mathrm{PVC}$ with $3 \mathrm{~mm}$ particle size were processed after carefully optimizing all process parameters except for the 
rotational direction of the magnetic drum. Figures 4 and 5 show the separability of mixtures of $\mathrm{Al}-\mathrm{PVC}$ and $\mathrm{Cu}-\mathrm{PVC}$, respectively, by employing Bakker ECS with a forward or clockwise rotation of the drum. It can be seen that small conducting particles like $\mathrm{Al}$ and $\mathrm{Cu}$ are either mixed up with the non-conducting ones or distributed in the collection bins that are closer to the magnetic drum.

Analysis of the material distribution indicates that it is difficult to separate small metal particles from non-metal ones selectively, when the magnetic drum rotates in the "Forward" mode. It has been found, though, that if the magnetic drum rotates in the "Backward" or counterclockwise manner, separation of small conducting particles from non-conducting ones is improved drastically. It is shown in Figs. 6 and 7 that more than $80 \%$ of $\mathrm{Al}$ and $\mathrm{Cu}$ of $3 \mathrm{~mm}$ size is distributed in the collection bins which are farther away from the magnetic drum. In addition, as was anticipated, non-conducting PVC particles have approximately consistent distribution in Figs. 4-7, since the oscillating direction of the magnetic field has no effect on non-conductors.

Similar results were obtained by using Eriez ECS which permits both "Forward" and "Backward" rotation of the magnetic drum.



FIGURE 4 Material distribution in the collection bins for $\mathrm{Al}$ and PVC by Bakker ECS (particle size $=3 \mathrm{~mm}$, belt speed $=1.6 \mathrm{~m} / \mathrm{s}$, drum speed $=3000 \mathrm{rpm}$, forward rotation). 


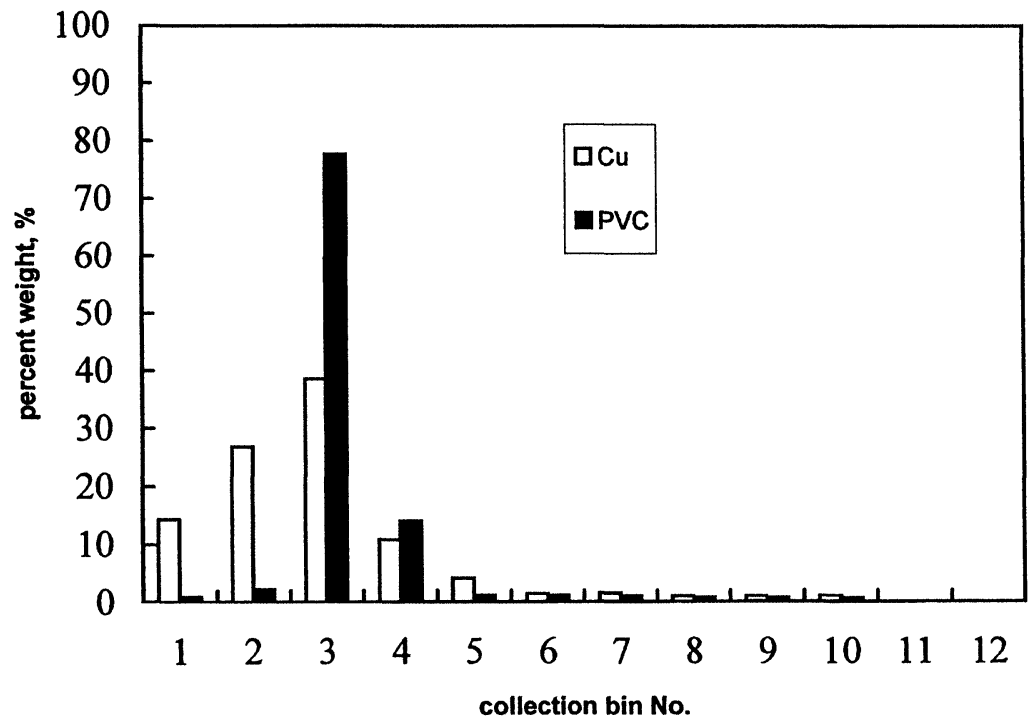

FIGURE 5 Material distribution in the collection bins for $\mathrm{Cu}$ and PVC by Bakker ECS (particle size $=3 \mathrm{~mm}$, belt speed $=1.6 \mathrm{~m} / \mathrm{s}$, drum speed $=3000 \mathrm{rpm}$, forward rotation).

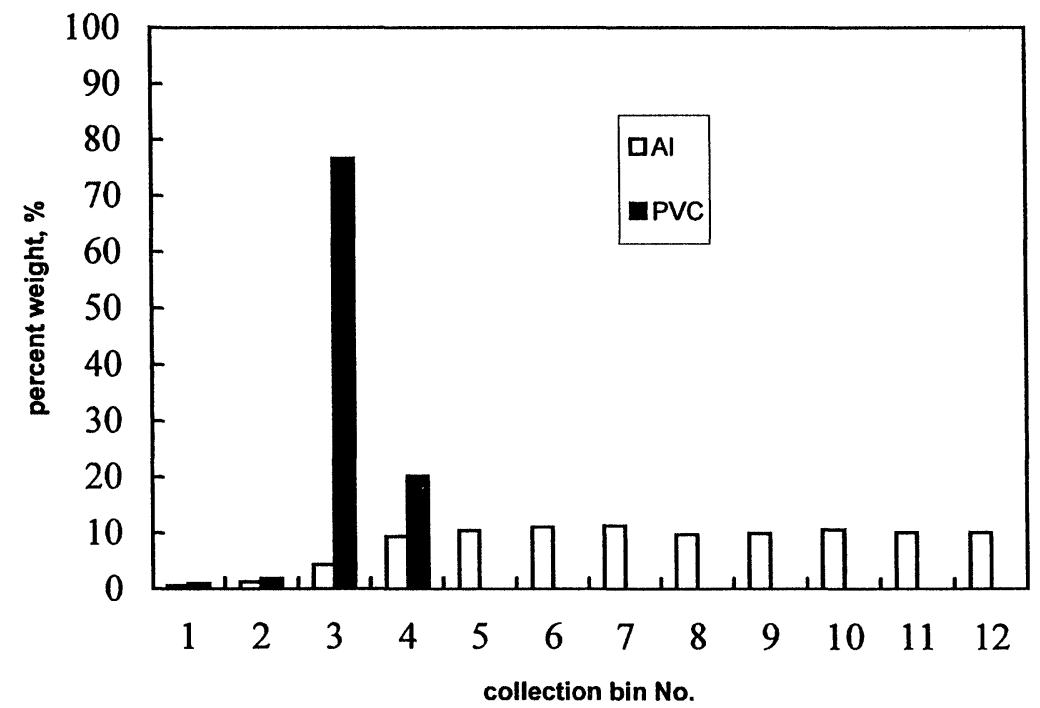

FIGURE 6 Material distribution in the collection bins for Al and PVC by Bakker ECS (particle size $=3 \mathrm{~mm}$, belt speed $=1.6 \mathrm{~m} / \mathrm{s}$, drum speed $=3000 \mathrm{rpm}$, backward rotation). 




FIGURE 7 Material distribution in the collection bins for $\mathrm{Cu}$ and PVC by Bakker ECS (particle size $=3 \mathrm{~mm}$, belt speed $=1.6 \mathrm{~m} / \mathrm{s}$, drum speed $=3000 \mathrm{rpm}$, backward rotation).

Figure 8 shows that approxiately $85 \% \mathrm{Al}$ can be separated from a mixture of $\mathrm{Al}$ and $\mathrm{PVC}$ of $3 \mathrm{~mm}$ size with almost $100 \%$ purity, as the magnetic drum spins in "Backward" direction. However, with the magnetic drum spinning in the "Forward" mode, less than $50 \%$ of Al can be recovered.

Unfortunately Huron ECS can be operated only in the "Forward" mode. The material distribution of the mixtures of $\mathrm{Al}-\mathrm{PVC}$ and $\mathrm{Cu}-$ PVC is presented in Figs. 9 and 10. It appears that when compared to Bakker ECS in the "Forward" mode, less conducting particles are mixed up with non-conducting ones. Yet, selective separation of small metal particles from non-metal ones is still difficult.

Based on a comparative investigation on three belted-drum ECS, it is found that a selective separation of metal particles below $5 \mathrm{~mm}$ may be established by spinning the magnetic drum in the "Backward" mode. This is referred to as the "backward phenomenon" in the present study. Therefore, the rotating belted-drum ECS tentatively designed for processing small particles below $5 \mathrm{~mm}$ shall incorporate a "Backward" mode like the Bakker and Eriez ECS, enabling the magnetic drum to rotate backwards. 


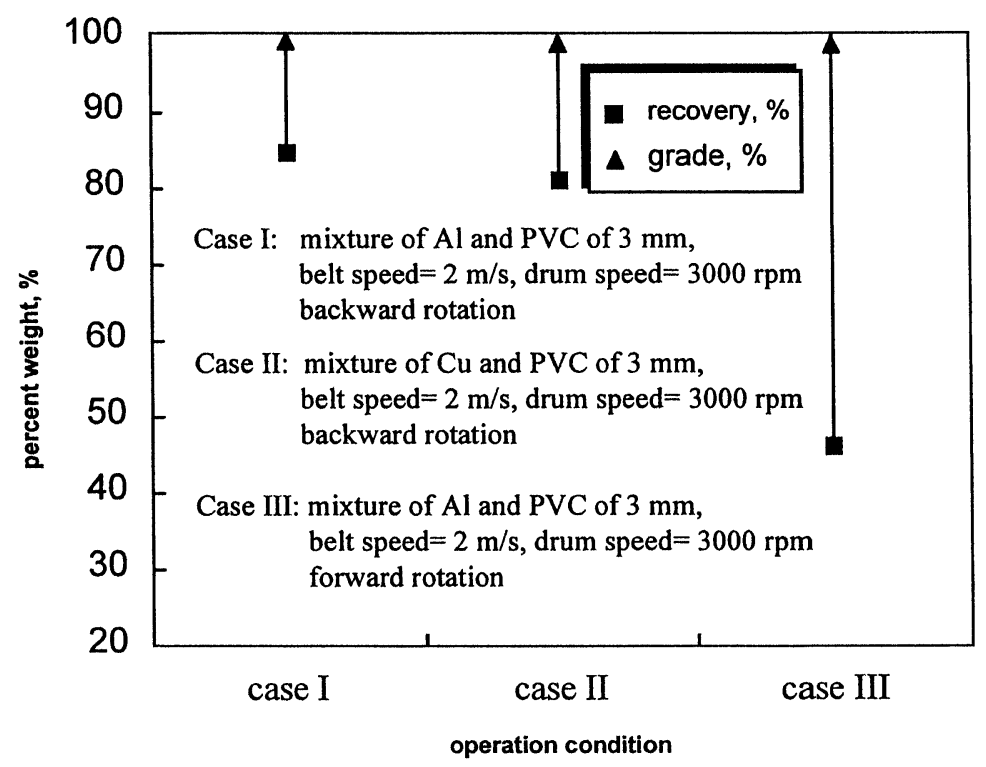

FIGURE 8 Separation results of binary mixtures by using Eriez ECS.

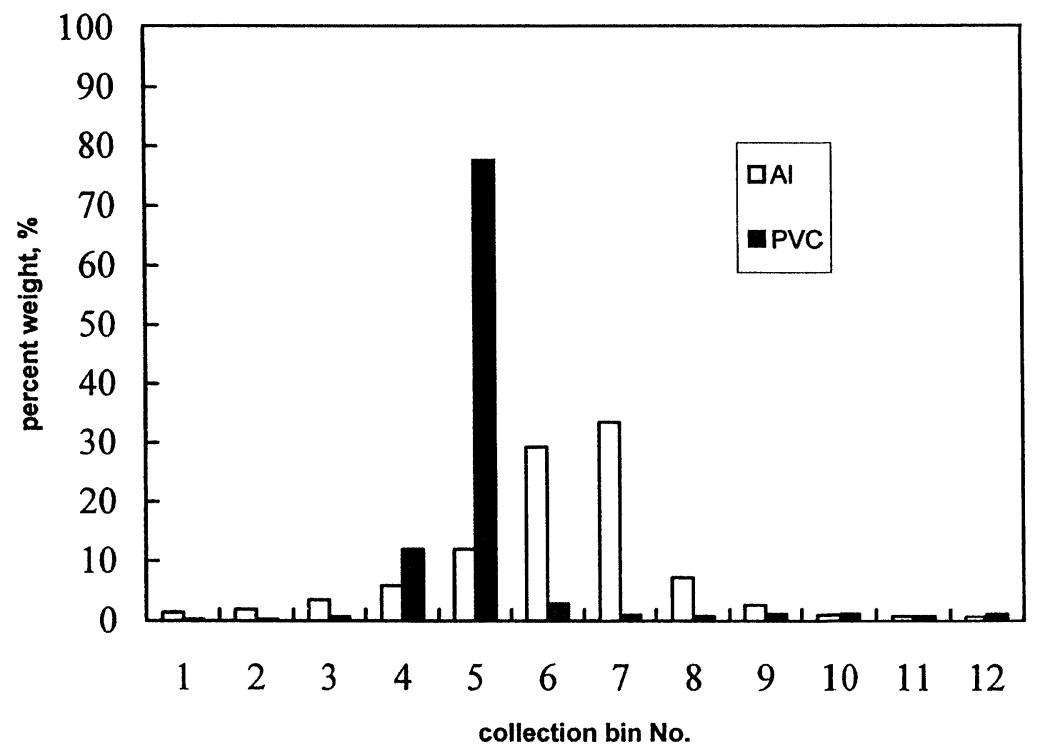

FIGURE 9 Material distribution in the collection bins for $\mathrm{Al}$ and PVC by Huron ECS (particle size $=3 \mathrm{~mm}$, belt speed $=2 \mathrm{~m} / \mathrm{s}$, drum speed $=3000 \mathrm{rpm}$, forward rotation). 




FIGURE 10 Material distribution in the collection bins for $\mathrm{Cu}$ and PVC by Huron ECS (particle size $=3 \mathrm{~mm}$, belt speed $=2 \mathrm{~m} / \mathrm{s}$, drum speed $=3000 \mathrm{rpm}$, forward rotation).

\subsection{The Separation Results of Electronic Scrap by Belted-Drum ECS}

The traditional "burning and smelting" recycling technique for handling electronic scrap is, to a great extent, applied in practice, which is aimed at recovering precious metals and copper. It is known that efficient removal of $\mathrm{Al}$ by using modern ECS is able to facilitate the metallurgical process. Furthermore, an extra revenue, due to the high value of the recovered $\mathrm{Al}$, can be obtained. It is for those reasons that the eddy current separation technology is of a great interest for the electronic scrap recycling industry. A point of concern is that the liberation size of $\mathrm{Al}$ particles present is in general small. Our study [4] shows that, after a two-stage liberation about $50 \%$ of $\mathrm{Al}$ in the printed circuit boards is distributed in the $-7 \mathrm{~mm}$ fraction. With a view towards implementing an effective ECS for this specific material stream, two modern belteddrum ECS were attempted, with the results given in Table II.

Clearly, the results of Huron ECS show that it is able to recover almost all the $\mathrm{Al}$ particles in a single pass, with low quality of the 
TABLE II Separation results of the electronic scrap

\begin{tabular}{lrcc}
\hline & Weight, \% & Al grade, \% & Al recovery, \% \\
\hline Huron ECS & & & \\
Concentrate & 7.4 & 52.5 & 97.6 \\
Waste & 92.6 & 0.1 & 2.4 \\
$\quad$ Total & 100.0 & 4.0 & 100.0 \\
Bakker ECS (Forward mode) & & & \\
$\quad$ Concentrate & 1.8 & 84.1 & 36.0 \\
$\quad$ Waste & 98.2 & 2.7 & 64.0 \\
$\quad$ Total & 100.0 & 4.2 & 100.0 \\
Bakker ECS (Backward mode) & & & \\
$\quad$ Concentrate & 2.0 & 94.8 & 47.6 \\
$\quad$ Waste & 98.0 & 2.1 & 52.4 \\
$\quad$ Total & 100.0 & 4.0 & 100.0 \\
\hline
\end{tabular}

Al concentrate. It was indeed observed that a substantial proportion of plastics particles with $\mathrm{Cu}$ laminates report to the $\mathrm{Al}$ fraction. On the contrary, it can be seen that Bakker ECS is capable of producing a high quality $\mathrm{Al}$ product (about $95 \%$ purity) in a single pass, but the recovery is approximately $50 \%$ in the "Backward" operation mode. Also, Table II indicates that both the recovery and selectivity in the "Backward" mode is much better than in the "Forward" mode. It is noteworthy that the splitter of Bakker ECS can be adjusted so as to recover almost all $\mathrm{Al}$ particles in a single pass as does the Huron ECS, but the product quality will then deteriorate significantly. As a result, these two ECS will have a similar performance in terms of both recovery and grade of the product. The performance of Bakker ECS shall be enhanced, if the feed material is screened into $+5 \mathrm{~mm}$ and $-5 \mathrm{~mm}$ fractions, as a consequence of the "backward phenomenon". It is also expected that effective recovery of small Al particles will be realized by means of a multi-pass circuit configuration.

\section{DISCUSSION}

\subsection{The Separating Forces on Small Particles and the "Backward Phenomenon"}

Separation mechanisms of small particles in eddy current separation are different from those of large particles. The radial and tangential 
eddy current forces $\left(F_{\mathrm{r}}\right.$ and $\left.F_{\mathrm{t}}\right)$ as well as the force derived from the electromagnetic torque $\left(F_{\mathrm{T}}\right)$ are given by the authors in [3]. Therefore, radial and tangential accelerations $\left(a_{\mathrm{r}}\right.$ and $\left.a_{\mathrm{t}}\right)$ as well as the acceleration component from $F_{\mathrm{T}}\left(a_{\mathrm{T}}\right)$ can be expressed as:

$$
\begin{aligned}
& a_{\mathrm{r}}=\frac{2 \pi s s^{\prime 2} B^{\mathrm{a} 2}}{\mu_{0} \rho w} \frac{\left(\mu_{0} k \omega_{\mathrm{drum}} \sigma R^{2}\right)^{2}}{1+s^{\prime 2}\left(\mu_{0} k \omega_{\mathrm{drum}} \sigma R^{2}\right)^{2}} \\
& a_{\mathrm{t}}=\frac{2 \pi s s^{\prime} B^{\mathrm{a} 2}}{\mu_{0} \rho w} \frac{\mu_{0} k \omega_{\mathrm{drum}} \sigma R^{2}}{1+s^{\prime 2}\left(\mu_{0} k \omega_{\mathrm{drum}} \sigma R^{2}\right)^{2}} \\
& a_{\mathrm{T}}=\frac{s s^{\prime} B^{\mathrm{a} 2}}{\mu_{0} \rho R} \frac{\mu_{0} k \omega_{\mathrm{drum}} \sigma R^{2}}{1+s^{\prime 2}\left(\mu_{0} k \omega_{\mathrm{drum}} \sigma R^{2}\right)^{2}}
\end{aligned}
$$

where $s$ is the shape factor related to the magnetization of a particle, $s^{\prime}$ is the shape factor related to the characteristic decay time of eddy currents, $B^{\mathrm{a}}$ is the amplitude of the magnetic field, $k$ is the number of pairs of the magnets in a drum, $\omega_{\text {drum }}$ is the angular velocity of the magnetic drum, $R$ is the characteristic particle size, $w$ is the width of one pair of the magnets, $\sigma$ is the electrical conductivity, $\rho$ is the mass density and $\mu_{0}=4 \pi \times 10^{-7} \mathrm{Tm} / \mathrm{A}$.

For simplicity, the following analysis is done for a spherical particle, due mainly to the fact that the spherical particle is orientation-independent. In the case of Bakker ECS $\left(k=9\right.$ and $\left.\omega_{\text {drum }}=100 \pi \mathrm{rad} / \mathrm{s}\right)$, accelerations of aluminum particles, which are computed by using Eqs. (2)-(4), are given in Fig. 11, as a function of $\mu_{0} k \omega_{\mathrm{drum}} \sigma R^{2}$ (in which $R$ is variable from 1.0 to $25.0 \mathrm{~mm}$ ). It is clear from Fig. 11 that, for a small particle, the dominant acceleration is the one from the electromagnetic torque and the radial acceleration is negligible, whereas for a large particle the predominant acceleration is in the radial direction. Thus, it follows, in terms of Fig. 11, that:

$$
\begin{aligned}
& a_{\mathrm{T}} \gg a_{\mathrm{t}}>a_{\mathrm{r}} \approx 0 \quad(R<5 \mathrm{~mm}) \\
& a_{\mathrm{r}} \gg a_{\mathrm{t}}<a_{\mathrm{T}} \quad(R>20 \mathrm{~mm}) .
\end{aligned}
$$

Evaluation of Eq. (2) shows that the radial force acting on a small particle is so feeble that it is unable to lift up the particle, which instead rotates with the field due to a strong electromagnetic torque. Figure 12 illustrates the rotation of a small conducting particle with the field and the forces involved. It is argued that, if the magnetic drum rotates 


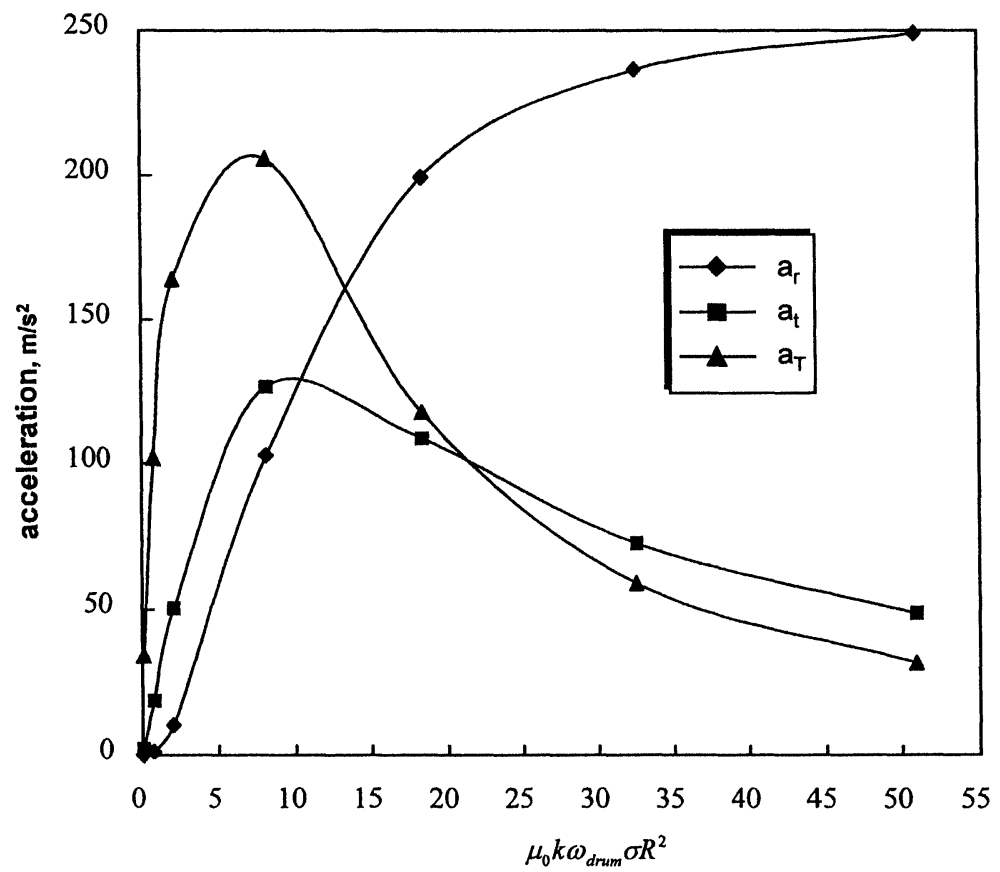

FIGURE 11 Accelerations of $\mathrm{Al}$ particles resulting from eddy current forces as a function of $\mu_{0} k \omega_{\text {drum }} \sigma R^{2}$.

clockwise or in the "Forward" mode, the dynamic frictional force $\left(F^{\text {fric }}\right)$ as a result of the electromagnetic torque will be anti-parallel (backward) to the tangential force $\left(F_{t}\right.$, forward) as indicated by the solid line shown in Fig. 12. On the other hand, if the magnetic drum rotates counterclockwise or in the "Backward" mode, the tangential force is directed backwards and the frictional force is directed forwards. Consequently, selective separation of small particles will be determined by a competition between the tangential eddy current force and the dynamic frictional force. In effect, this concept can be quantified as:

$F_{\mathrm{t}}>F^{\text {fric }} \Rightarrow$ the magnetic drum shall rotate clockwise or forwards

$F_{\mathrm{t}}<F^{\text {fric }} \Rightarrow$ the magnetic drum shall rotate counterclockwise or backwards. 


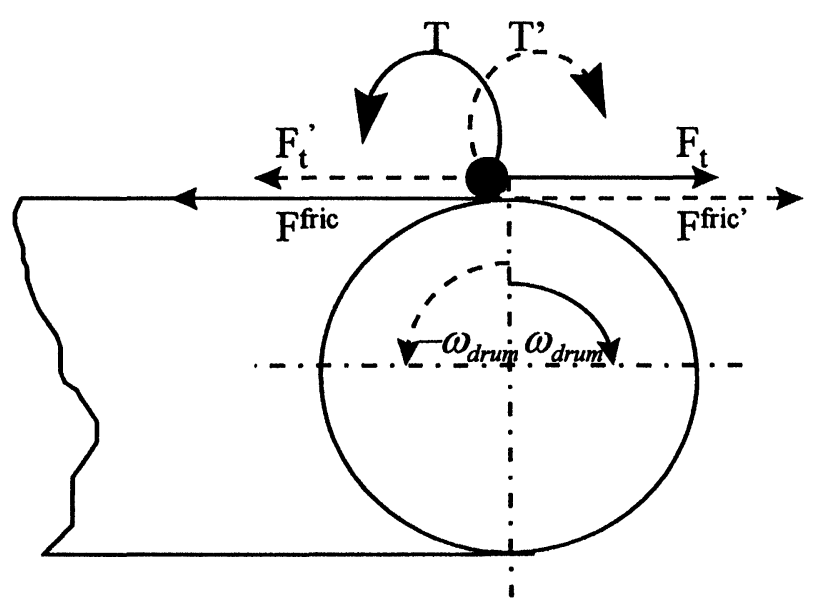

Note that the dashed line is relevant to the "Backward" rotation

FIGURE 12 Eddy current forces, electromagnetic torques and competing forces on small particles.

Since $F_{\mathrm{r}}$ is negligible, we have $F^{\mathrm{fric}}=f^{\mathrm{d}} m g$ where $f^{\mathrm{d}}$ is the dynamic frictional coefficient, $m$ is the mass of the particle and $g$ is the acceleration due to gravity. Equations (7) and (8) are also expressed as:

$a_{\mathrm{t}}>f^{\mathrm{d}} g \Rightarrow$ the magnetic drum shall rotate clockwise or forwards

$a_{\mathrm{t}}<f^{\mathrm{d}} g \Rightarrow$ the magnetic drum shall rotate counterclockwise or backwards.

For the rubber belt of Bakker ECS that is used in the present study, $f^{\text {d }}$ is about 1.1 on average, so that $f^{\mathrm{d}} g$ is about $10 \mathrm{~m} / \mathrm{s}^{2}$. It must also be pointed out that the belt is used for such a long time that it is covered with dirt, thereby rendering the belt surface even rougher.

The average tangential acceleration of small particles as a function of the drum speed and particle size are shown in Fig. 13. It is clear that, at 50 rps drum speed which is the operating condition for Figs. 4-7, the average tangential acceleration of $3 \mathrm{~mm} \mathrm{Al}$ particles is much smaller than $10 \mathrm{~m} / \mathrm{s}^{2}$ whilst the average tangential acceleration of $5 \mathrm{~mm} \mathrm{Al}$ particles is larger than $10 \mathrm{~m} / \mathrm{s}^{2}$. Therefore, it is predicted that in order to separate out $\mathrm{Al}$ particles of $5 \mathrm{~mm}$, the magnetic drum shall rotate in the 


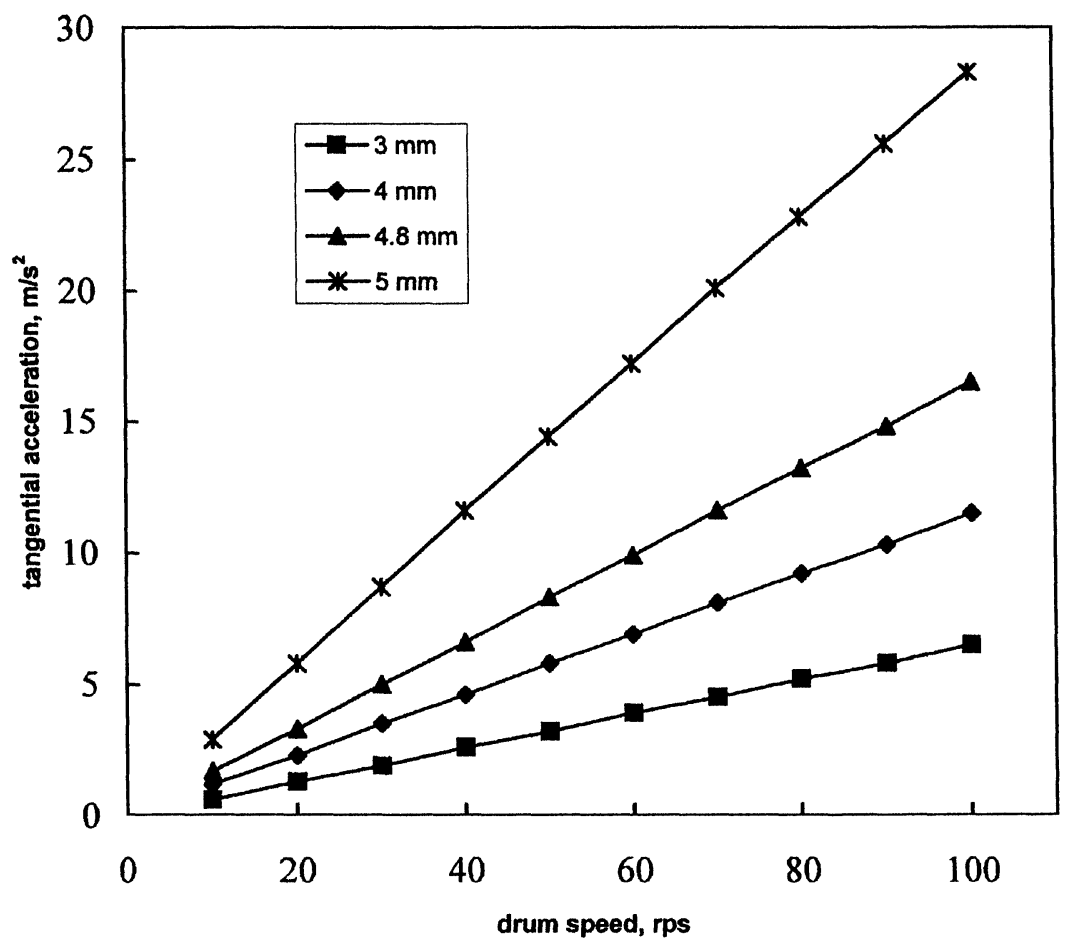

FIGURE 13 Tangential acceleration as a function of drum speed and particle size.

"Forward" mode. This is in line with the experimental work, as shown in Figs. 14 and 15.

Alternatively, the above argument can be verified further by calculating the average horizontal displacements of $3 \mathrm{~mm} \mathrm{Al}$ particles for the present experiments. It follows that:

$$
S_{\perp}=\frac{1}{2} g \Delta t^{2}
$$

where $S_{\perp}$ is the vertical displacement of a particle, and $\Delta t$ is the time needed for that vertical displacement.

Since $S_{\perp}=0.6 \mathrm{~m}$, we have $\Delta t=0.35 \mathrm{~s}$. If the magnetic drum rotates backwards, the particle rolls forwards on the belt. The time for the particle from starting to roll to leaving the belt $\left(\Delta t_{\text {roll }}\right)$ is estimated as:

$$
\Delta t_{\text {roll }}=\frac{S_{\text {roll }}}{V_{\text {belt }}} \text {. }
$$




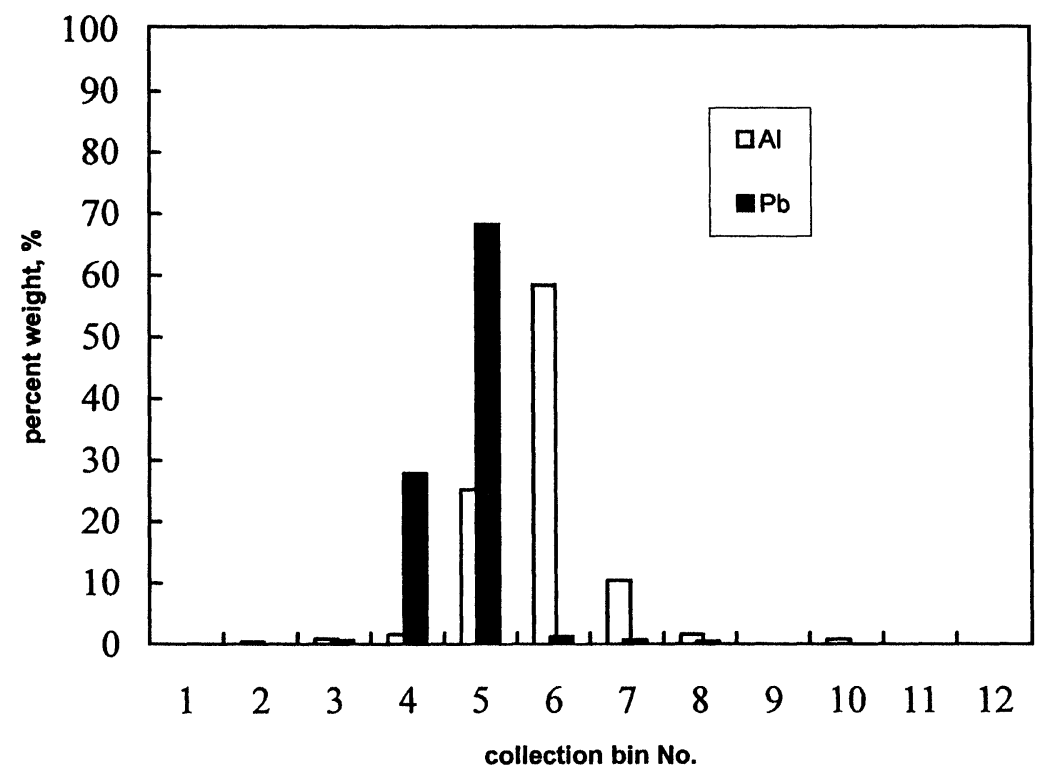

FIGURE 14 Material distribution in the collection bins for $\mathrm{Al}$ and $\mathrm{Pb}$ by Bakker ECS (particle size $=5 \mathrm{~mm}$, belt speed $=1.6 \mathrm{~m} / \mathrm{s}$, drum speed $=3000 \mathrm{rpm}$, forward rotation).

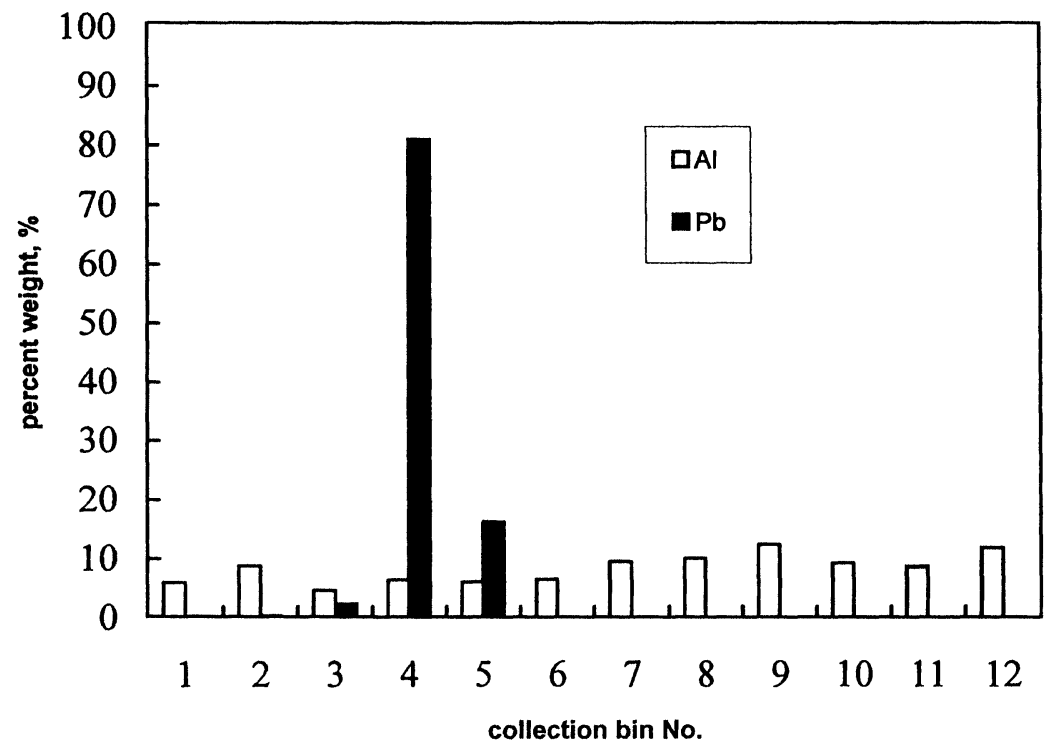

FIGURE 15 Material distribution in the collection bins for $\mathrm{Al}$ and $\mathrm{Pb}$ by Bakker ECS ( particle size $=5 \mathrm{~mm}$, belt speed $=1.6 \mathrm{~m} / \mathrm{s}$, drum speed $=3000 \mathrm{rpm}$, backward rotation). 
It was measured that the distance for the particle from starting to roll to leaving the belt $\left(S_{\text {roll }}\right)$ is about $0.11 \mathrm{~m}$ and the belt speed $\left(V_{\text {belt }}\right)$ is $1.6 \mathrm{~m} / \mathrm{s}$, such that $\Delta t_{\text {roll }}=0.069 \mathrm{~s}$. Therefore, we are now able to estimate the average horizontal displacement $\left(S_{\|}\right)$of $3 \mathrm{~mm} \mathrm{Al}$ particles as:

$$
S_{\|}=\left(V_{\text {belt }}+a_{\|} \Delta t_{\text {roll }}\right) \Delta t \text {. }
$$

Since $a_{\|}=f^{\mathrm{d}} g-a_{\mathrm{t}}=10.78-3.2=7.58 \mathrm{~m} / \mathrm{s}^{2}$, we obtain $S_{\|}=0.735 \mathrm{~m}=$ $73.5 \mathrm{~cm}$, as is in line with the results shown in Fig. 6. It is worth mentioning that the dynamic frictional coefficient $f^{\mathrm{d}}$ varies remarkably [5]. This is the reason why in Fig. 6 the distribution of $3 \mathrm{~mm} \mathrm{Al}$ particles is widespread.

We conclude that effective separation of $3 \mathrm{~mm}$ Al particles from nonmetallic particles can be realized only by rotating the magnetic drum in the "Backward" mode. According to Eqs. (9) and (10), the critical particle size, at which the rotational direction of the magnetic drum should be changed from forward to backward or vice versa, is about $4.8 \mathrm{~mm}$.

\subsection{The Enhancement of Separation Selectivity for Small Particles}

As previously discussed, problems associated with selective separation of small particles are: (1) negligible radial eddy current force, implying that a small particle cannot be lifted off the belt; (2) competition between the tangential eddy current force and the dynamic frictional force as a result of the electromagnetic torque.

In an effort to address those problems, the following attempts may be made to improve the separation selectivity of small particles:

(1) Enhancement of the tangential eddy current force with respect to the effects of the electromagnetic torque by optimizing the magnetic drum system.

(2) Elimination of the competing forces like the dynamic frictional force created by the electromagnetic torque.

(3) Introduction of the assistant separating forces, for instance, by converting the effects of the electromagnetic torque to a separating effect.

(4) Effective combinations thereof.

As is clearly indicated by Eqs. (3) and (4), the tangential eddy current force will be enhanced by an increase of the magnetic field strength and 
a decrease of the magnet pole width. However, a change of the magnet pole width has no effect on the electromagnetic torque. Reflecting this concept, a recent design is a prototype TNO ECS, which has been conceived by the Netherlands Organization for Applied Scientific Research (TNO), Apeldoorn, the Netherlands. This new ECS will be discussed in Part II of this paper series. Other devices incorporating our concepts mentioned above will be described in detail in Part II.

\section{CONCLUSIONS}

The present study yields the following major findings:

(1) Metal particles smaller than $5 \mathrm{~mm}$ can be separated effectively by the Bakker and Eriez ECS, only if the magnetic drum rotates backwards.

(2) The "backward phenomenon" results from the competition between the tangential eddy current force and the dynamic frictional force created by the electromagnetic torque.

(3) The critical particle size for which the magnetic drum rotates backwards is about $4.8 \mathrm{~mm}$.

\section{Acknowledgements}

The authors wish to express their gratitude to the Minerals and Metals Recycling Research Center (MIMER), Luleå University of Technology, Sweden, for financial support. Appreciation also goes to the Department of Waste and Materials Technology, The Netherlands Organization for Applied Scientific Research (TNO), Apeldoorn, the Netherlands, for assistance and providing an Eriez Model 1222 laboratory eddy current separator.

\section{References}

[1] P. Rem, P. Leest and A. van der Akker, A model for eddy-current separation. Int. J. Min. Proc., 49 (1997) 193-200.

[2] P. Rem, E. Beunder and A. van der Akker, Simulation of eddy-current separators. IEEE Transactions on Magnetics, 34 (1998) 2280-2286. 
[3] S. Zhang, P. Rem and E. Forssberg (1998), Particle trajectory simulation of twodrum eddy current separators. Manuscript submitted to Resources, Conservation \& Recycling.

[4] S. Zhang and E. Forssberg, Electronic scrap characterization for materials recycling. Journal of Waste Management \& Resource Recovery, 3 (1997) 157-167.

[5] D. Stoianovici and Y. Hurmuzlu, A critical study of the applicability of rigid-body collision theory. Journal of Applied Mechanics, 63 (1996) 307-316. 